\title{
Clinical Factors Associated With Overuse of Asthma Reliever Medication
}

\author{
Urrutia I', Delgado J², Domínguez-Ortega J33, Mascarós $\mathrm{E}^{4}$, Pérez $\mathrm{M}^{5}$, Resler $\mathrm{G}^{5}$, Plaza $\mathrm{V}^{6}$, on behalf of \\ the MISTRAL Investigators Group
}

\author{
'Respiratory Department, Galdakao Hospital, OSI Barrualde-Galdakao, Biscay, Spain \\ ${ }^{2}$ Allergy Department, Hospital Virgen Macarena, Sevilla, Spain \\ ${ }^{3}$ Department of Allergy, Healthcare Research Institute IdiPAZ, CIBER de Enfermedades Respiratorias, CIBERES, Hospital Universitario La Paz, \\ Madrid, Spain \\ ${ }^{4}$ Medicina de Familia y Comunitaria, Centro de Salud Fuente de San Luis, Valencia, Spain, Spain \\ ${ }^{5}$ Medical Department AstraZeneca, Barcelona, Spain \\ ${ }^{6}$ Department of Respiratory Medicine, Hospital de la Santa Creu i Sant Pau, Institut d'Investigació Biomédica Sant Pau (IIB Sant Pau), Barcelona, Spain
}

J Investig Allergol Clin Immunol 2020; Vol. 30(1): 42-48

doi: 10.18176/jiaci.0387

\begin{abstract}
Objective: Our aim was to evaluate the relationship between the clinical factors of asthma and the use of reliever medication. Methods: We performed an observational cross-sectional study in Spain. The study population comprised patients aged $\geq 12$ years diagnosed with persistent asthma according to the criteria of the Global Initiative for Asthma and receiving maintenance treatment for at least 12 months. Use of reliever medication was classified as low use of reliever medication (LURM) ( $\leq 2$ times/wk) and high use of reliever medication (HURM) ( $\geq 3$ times/wk). A variety of clinical variables and patient-reported outcomes (PROs) were recorded (eg, scores on the Asthma Control Questionnaire-5 [ACQ-5] and Test of Adherence to Inhalers [TAI]).

Results: A total of 406 patients were recruited. Mean (SD) age was 44.3 (17.9) years, and 64\% were women. Reliever medication was used $\leq 2$ times/wk in $76.1 \%$. Bivariate analysis showed that HURM was related to smoking habit, unscheduled emergency department visits, hospital admissions, higher doses of inhaled corticosteroid, and night awakenings in the previous 4 weeks $(P<.001)$. The multivariate analysis showed a higher risk of using reliever medication in smokers and former smokers, when the number of night awakenings increased, in cases of self-perception of partially controlled or uncontrolled asthma, or when asthma is uncontrolled according to the ACQ-5. Conclusions: Our study identifies the potential of poor use of reliever medication in the last week as an alarm signal for disease-related parameters such as exacerbations, poor asthma control, and disease severity.
\end{abstract}

Key words: Reliever medication. Reliever medication. Asthma control.

\section{Resumen}

Objetivo: Nuestro objetivo fue evaluar la relación entre parámetros clínicos del asma y el uso de medicación de rescate. Métodos: Estudio observacional de corte transversal realizado en España. El estudio reclutó pacientes $\geq 12$ años diagnosticados con asma persistente según los criterios de GINA y que recibieron tratamiento de mantenimiento durante al menos 12 meses. El uso de la medicación de rescate fue dicotomizado: bajo uso de medicación de rescate (LURM) ( $\leq$ dos veces/semana) o alto uso de medicación de rescate (HURM) ( $\geq$ tres veces/semana). Se registraron una variedad de variables clínicas y resultados notificados por los pacientes (PRO), como el Cuestionario de Control del Asma-5 (ACQ-5) y la Prueba de Adherencia a Inhaladores (TAI).

Resultados: Se reclutaron 406 pacientes, de 44,3 [17,9] años edad media (DE) y un 64\% de mujeres. En el 76,1\% se utilizó medicación de rescate $\leq$ dos veces por semana. El análisis bivariante mostró que la HURM estaba relacionada con el hábito de fumar, las visitas no programadas a urgencias, ingresos hospitalarios, aumento de las dosis de corticosteroides inhalados, aumento en la terapia y los despertares nocturnos en las últimas cuatro semanas $(p<0,001)$. El análisis multivariado mostró un mayor riesgo de usar medicación de rescate en fumadores y exfumadores, cuando aumentó el número de despertares nocturnos, en casos de autopercepción de asma parcialmente controlada o no controlada, o cuando el asma no está controlada en base al ACQ-5.

Conclusiones: Nuestro estudio identifica la posibilidad de utilizar el aumento de la medicación de rescate en la última semana como una señal de alarma para algunos parámetros de la enfermedad, como exacerbaciones, mal control del asma y gravedad de la enfermedad.

Palabras clave: Asma. Medicación de rescate. Control del asma. 


\section{Introduction}

Despite the availability of effective treatments and consensus guidelines for the management of asthma [1-3], disease control is still suboptimal in approximately half of the patients treated in Europe [4-7] and in Spain [8]. In addition, there is evidence that poor asthma control is associated with an increased risk of exacerbations, a decrease in quality of life, a reduction in productivity, and an increase in the use of health resources $[6,7,9,10]$. Furthermore, lack of control has been associated with an increased risk of hospitalization [11].

In clinical practice, the REcognise Asthma and LInk to Symptoms and Experience (REALISE) survey evaluated social aspects, symptoms, levels of asthma control according to guidelines, and how the symptoms and indicators of exacerbations were related to control and therapeutic steps in 8000 patients from 11 European countries [12]. The results showed that $45 \%$ of patients had poor disease control and that more than $40 \%$ used their reliever medication $\geq 3$ times during the previous week. The most frequent use was observed in those receiving a combination of inhaled corticosteroids (ICSs) and a long-acting $\beta$-agonist (LABA) in an inhaler ( $\geq 10$ times in the previous week). Furthermore, $50 \%$ of patients responded that they did not take their maintenance therapy as prescribed, and more than half had had their inhaler technique reviewed by their doctor in the previous year.

Asthma patients have great confidence in reliever medication, and some do not recognize increased use as a sign of disease deterioration and the need for adjustment of treatment. Patients' perceptions of their asthma control differ from the actual degree of control. Many asthma patients do not consider themselves to be sick and are not worried about their condition. Since they believe their disease is controlled, they do not associate their symptoms with poor control. In fact, they overestimate their control and underestimate the severity of their disease, indicating that patients tolerate their symptoms and the limitations they cause $[6,13]$.

Reliever therapies such as short-acting $\beta$-agonists (SABAs) should be reserved for occasional symptoms relief $[12,13]$. However, SABAs are the primary mode of treatment for many patients $[15,16]$. The aim of the present study was to evaluate the relationship between the use of reliever medication (adequate or excessive use) and clinical factors associated with asthma. We also assessed whether misuse of SABAs was a marker of poor asthma control in patients with persistent asthma who took high doses of reliever medication while on inhaled maintenance therapy for at least 1 year.

\section{Patients and Methods}

The present study was a real-world, observational, cross-sectional study conducted by Spanish pulmonologists, allergists, and general practitioners according to the International Guidelines for Ethical Review of Epidemiological Studies, the Declaration of Helsinki and all its amendments, and national regulations. The study was approved by the Ethics Committee of Hospital de la Santa Creu i Sant Pau, Barcelona, Spain, and all patients provided their written informed consent to participate.

\section{Patient Population}

Patients were recruited using a consecutive nonprobability sampling technique over a 3-month period. They had to be aged $\geq 12$ years and diagnosed with persistent asthma according to the GINA criteria at least 12 months before the inclusion date. They also had to have used maintenance therapy for at least 12 months before inclusion, although they may have received various other treatment steps throughout the year. Patients were excluded if they had already participated in a clinical trial in the previous 3 months, had another severe illness that altered perception (eg, fibromyalgia, severe anxiety, depression, or schizophrenia), were not able to understand the information provided in the patient information sheet, or were not able to provide informed consent.

\section{Evaluation of Patients' Characteristics}

The type of reliever medication used and the number of administrations within the previous 30 days was recorded to characterize use of the medication. Asthma control was assessed using the Asthma Control Questionnaire-5 (ACQ-5) (controlled $[\leq 0.75]$, partially controlled [0.76-1.49], and uncontrolled $[\geq 1.5]$ ) [8] and according to the Spanish Guideline on the Management of Asthma (GEMA) [3]. Self-perception of the degree of asthma control was measured using a Likert-type scale, where asthma was graded as controlled, partially controlled, or not controlled. Each patient reported exacerbations, which were confirmed in the clinical history. An exacerbation was defined as an acute worsening of asthma symptoms leading to the need to increase the dose of ICS or to increase treatment by 1 step, use of systemic corticosteroids, visits to the emergency department, other unscheduled health care visits, or need for hospitalization.

Physicians also collected sociodemographic data, smoking habit (smoker, former smoker, or nonsmoker), clinical history of asthma (date of diagnosis, severity of the disease, number of emergency department visits in the previous year, number of admissions, unscheduled visits, number of days with night awakenings within the previous 4 weeks, average consumption of reliever medication per week, type of drugs used on demand for symptom relief), concomitant diseases, chronic concomitant treatment, and maintenance treatment for asthma. Finally, adherence to maintenance treatment was assessed using the Test of Adherence to Inhalers (TAI) questionnaire [18], which comprises 10 self-administered questions for the patient and 2 for the health care professional in order to define the degree of adherence and suggest a pattern of nonadherence to inhalation therapy (erratic, deliberate, or unwitting).

\section{Statistical Analysis}

For sample size calculation, it was estimated that disease is controlled in $60.2 \%$ of patients using treatments similar to the study treatment [10]; therefore, a ratio of 1.5 to 1 of controlled to uncontrolled disease was expected. As there were no reported data on the relationship between control and overuse of reliever medication or on the proportion of patients with adequate vs excessive use, the principle of maximum variance $(50 \%)$ was assumed. Assuming an $\alpha$ risk of 0.05 , a power of $80 \%$ in a 2 -sided test, and a maximum patient loss 
of $5 \%$, it was necessary to include 300 patients whose disease was expected to be controlled and 200 whose disease was expected to be uncontrolled in order to detect $a \geq 13 \%$ difference between the groups.

For the statistical analysis, the use of reliever medication was classified into 2 groups: low use of reliever medication (LURM) $(\leq 2$ times/wk) and high use of reliever medication (HURM) ( $\geq 3$ times/wk), according to the criteria of the GINA and GEMA 4.0 guidelines [3]. Mann-Whitney hypothesis tests (unpaired data) were used for the variables that were not adjusted to the normal distribution. The Fisher exact test was used in the analysis of the contingency tables and for the comparison of distributions. A logistic regression analysis was carried out to identify factors related to asthma control. The factors included were age, gender, smoking habit, asthma severity, number of times reliever medication is used, number of hospital admissions, number of exacerbations, type of reliever medication, nasal polyposis, and self-perception of asthma control. Finally, an exploratory multivariate analysis of the use of reliever medication ( $<$ vs $\geq 3$ times/wk) was performed based on the following factors: smoking habit, time from diagnosis, asthma severity, visits to the emergency department, night awakenings, hospital admission, dose increases, unscheduled visits, therapy step upgrading, exacerbations, self-perception of asthma control, ACQ-5 score, unwitting nonadherence, concomitant respiratory or skin disease, and maintenance therapy. Only factors that reached a $P$ value $<.20$ in the bivariate analyses were included in the multivariate model. The data were analyzed using PASW Statistics for Windows, Version 18.0 (SPSS Inc.).

\section{Results}

\section{Patients' Characteristics}

A total of 407 patients participated in the study from November 2016 to February 2017; 1 patient was excluded owing to severe illness that altered perception. The main comorbidities were rhinitis $(48.5 \%)$, hypertension $(17 \%)$, gastroesophageal reflux (11\%), nasal polyposis $(9.4 \%)$, dyslipidemia $(6.7 \%)$, atopic dermatitis $(6.7 \%)$, diabetes (4.4\%), and chronic obstructive pulmonary disease $(1.5 \%)$ (Table 1). Asthma therapies are shown in Table 2. The mean (SD) number of inhalations in the previous 7 days was 2.8 (6.2). Over the previous 30 days, reliever medication was used for 7.2 (20.3) days.

When asthma maintenance therapy was evaluated in LURM and HURM patients, $15.5 \%$ and $16.5 \%$ used only ICSs $(P=.873), 85.8 \%$ and $89.7 \%$ used a combination of ICSs and LABAs $(P=.393), 31.7 \%$ and $44.3 \%$ used a leukotriene receptor antagonist $(P<.05), 9.4 \%$ and $10.3 \%$ used an antiIgE agent (omalizumab) $(P=.844)$, and $1 \%$ and $10.3 \%$ used systemic corticosteroids $(P<.001)$. Most patients $(76.1 \%)$ used reliever medication $\leq 2$ times per week and almost a quarter of the study population misused their medication. Table 1 shows the main characteristics of the sample and divides patients according to their frequency of use of asthma reliever medication. The frequency of smokers was higher in HURM than in LURM patients; a sedentary lifestyle was more prevalent in patients who misused their reliever medication. Asthma was more severe in the HURM group than in the LURM group. Furthermore, in the HURM group, there were

Table 1. Patient Characteristics

\begin{tabular}{|c|c|c|c|c|}
\hline & $\begin{array}{c}\text { Total } \\
(\mathrm{N}=406)\end{array}$ & $\begin{array}{c}\text { LURM } \\
(\leq 2 \text { times/wk }) \\
(n=309)\end{array}$ & $\begin{array}{c}\text { HURM } \\
(\geq 3 \text { times/wk) } \\
(n=97)\end{array}$ & $P$ Value \\
\hline Mean (SD) age, y & $44.3(17.9)$ & $44.1(18.5)$ & $44.9(15.9)$ & .689 \\
\hline $\begin{array}{l}\text { Gender, No. (\%) } \\
\text { Women }\end{array}$ & $260(64)$ & $194(62.8)$ & $66(68.0)$ & .396 \\
\hline $\begin{array}{l}\text { Smoking habit, No. }(\%) \\
\text { Smoker } \\
\text { Former smoker } \\
\text { No smoker } \\
\text { Mean (SD) time from diagnosis }\end{array}$ & $\begin{array}{l}41(10.1) \\
114(28.1) \\
251(61.8) \\
13.2(11.2)\end{array}$ & $\begin{array}{c}22(7.1) \\
81(26.2) \\
206(66.7) \\
13.6(11.1)\end{array}$ & $\begin{array}{c}19(19.6) \\
33(34.0) \\
45(46.4) \\
12.0(11.6)\end{array}$ & $P<.001$ \\
\hline $\begin{array}{l}\text { Asthma severity, No. (\%) } \\
\text { Mild } \\
\text { Moderate } \\
\text { Severe } \\
\text { Mean (SD) last eosinophil count } \\
\text { Mean (SD) number of visits to the emergency department } \\
\text { in the previous year } \\
\text { Mean (SD) number of night awakenings in the previous } 4 \text { weeks } \\
\text { Mean (SD) hospital admission in the previous year } \\
\text { Mean (SD) increase in ICS therapy in the previous year } \\
\text { Mean (SD) unscheduled visits in the previous year } \\
\text { Mean (SD) therapeutic step upgrade } \\
\text { Mean (SD) asthma exacerbations in the previous year }\end{array}$ & $\begin{array}{c}95(23.4) \\
218(53.7) \\
93(22.9) \\
0.5(0.7) \\
\\
0.6(1.2) \\
1.9(5.6) \\
0.1(0.4) \\
0.5(1.0) \\
0.8(1.8) \\
0.5(1.0) \\
1.3(2.3)\end{array}$ & $\begin{array}{c}85(27.5) \\
168(54.4) \\
56(18.1) \\
0.5(0.8) \\
0.3(0.8) \\
0.6(1.4) \\
0.1(0.3) \\
0.4(0.8) \\
0.5(0.9) \\
0.4(0.8) \\
0.9(2.0)\end{array}$ & $\begin{array}{c}10(10.3) \\
50(51.5) \\
37(38.1) \\
0.5(0.6) \\
1.3(1.9) \\
6.0(10.1) \\
0.2(0.6) \\
1.0(1.4) \\
1.7(3.2) \\
0.9(1.3) \\
2.4(2.9)\end{array}$ & $\begin{array}{c}P=.442 \\
\\
<.001 \\
<.001 \\
<.001 \\
<.001 \\
<.001 \\
<.001 \\
<.001\end{array}$ \\
\hline
\end{tabular}

Abbreviations: HURM, high use of rescue medication; ICS, inhaled corticosteroid; LURM, low use of rescue medication. 
Table 2. Asthma Treatments

\begin{tabular}{lc} 
& No. $(\%)$ \\
\hline Monotherapy, No. $(\%)$ & $64(15.8)$ \\
Budesonide & $35(8.6)$ \\
Fluticasone propionate & $12(3.0)$ \\
Mometasone furoate & $10(2.5)$ \\
Combination therapy & $352(86.7)$ \\
Budesonide/formoterol & $125(30.8)$ \\
Beclomethasone/formoterol & $84(20.7)$ \\
Fluticasone propionate/salmeterol & $72(17.7)$ \\
Fluticasone propionate/formoterol & $37(9.1)$ \\
Fluticasone furoate/vilanterol & $36(8.9)$ \\
Other therapies & \\
Long-acting muscarinic antagonist & $42(10.3)$ \\
Leukotriene receptor antagonists & $141(34.7)$ \\
Oral corticosteroids & $13(3.2)$ \\
Anti IgE-omalizumab & $39(9.6)$ \\
Immunotherapy & $34(8.4)$ \\
Rescue therapy in the last 7 d & \\
Salbutamol & $136(33.5)$ \\
Terbutaline & $52(12.8)$ \\
Ipratropium bromide & $19(4.7)$ \\
Budesonide/formoterol & $20(4.7)$ \\
Beclomethasone/formoterol & $15(3.7)$ \\
Fluticasone propionate/formoterol & $2(0.5)$ \\
\end{tabular}

more visits to the emergency department in the previous year, night awakenings in the previous 4 weeks, hospital admissions in the previous year, increases in ICS therapy in the previous year, unscheduled visits in the previous year, and upgraded therapeutic steps.

According to the TAI results, adherence to maintenance therapy was suboptimal: $67 \%$ and $70.1 \%$ of LURM and HURM patients, respectively, were nonadherent $(P=.620)$. It is notable that the prevalence of the unwitting pattern of nonadherence was higher in HURM patients than in LURM patients $(21.6 \%$ vs $12.9 \%, P=.05)$ (Figure 1$)$. No significant differences were noted in the remaining patterns, which were erratic in $64.4 \%$ and $68 \%$ of LURM and HURM patients, respectively, and deliberate in $41.1 \%$ and $46.4 \%$ of LURM

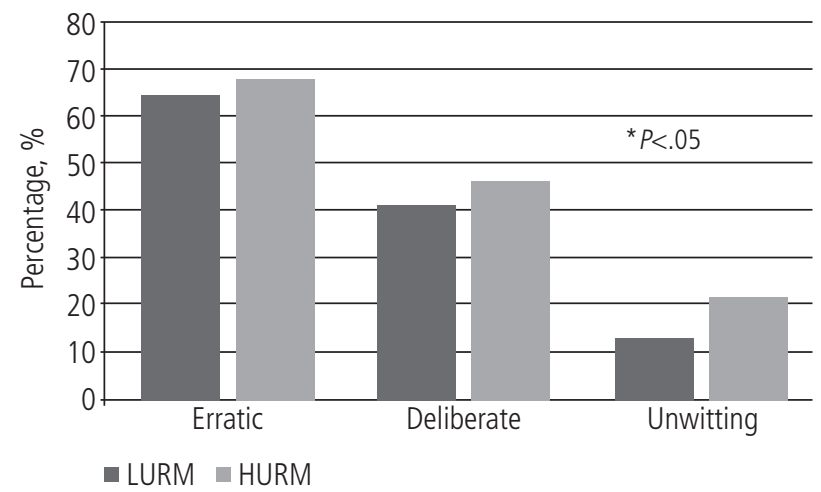

Figure 1. TAI profiles and use of relief medication. LURM indicates low use of reliever medication; HURM, high use of reliever medication.

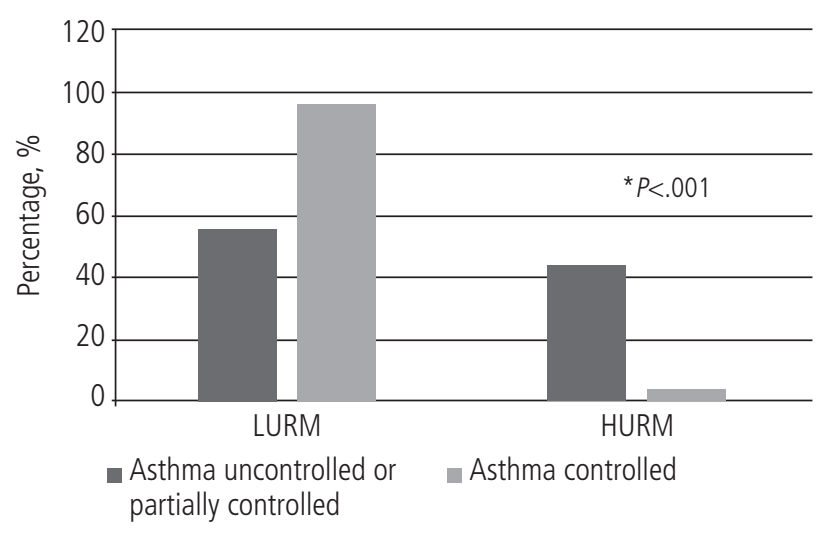

Figure 2. Asthma control and use of relief medication. LURM indicates low use of reliever medication; HURM, high use of reliever medication.

and HURM patients, respectively. Control of asthma was poorer in the HURM patients $(P<.001)$ (Figure 2$)$. When patients were asked about their perception of asthma control, $26.6 \%$ perceived asthma to be partially controlled and $10.6 \%$ uncontrolled. The concordance between the ACQ scores and patient self-perception was moderate ( $\kappa$ index, 0.476$)$.

The logistic regression analysis model of factors related to asthma control showed that older age, moderate asthma severity, $\geq 3$ doses of reliever medication, and salbutamol or beclomethasone-formoterol in the last 30 days were associated with a lower probability of controlling asthma (Table 3 ). In the exploratory model of factors related to the use of reliever medication, there was a higher risk of using reliever medication in smokers and former smokers, when the number of night awakenings increased, when the patient's self-perception was partially controlled or uncontrolled asthma, and when asthma was uncontrolled according to the ACQ-5 (Table 4).

\section{Discussion}

This study supports an association between excessive use of reliever medication and poor asthma control in patients on maintenance therapy. It also offers an overview of patients who misuse reliever medication, highlighting that factors such as smoking, night awakenings, and control assessed with the ACQ-5 are related to misuse. These findings can be incorporated into daily clinical practice. Although misuse of reliever medication has been widely investigated, the study design and the definition of misuse differ between studies. Fitzgerald et al [19] defined inappropriate use as 2 or more puffs of a SABA per week in the absence of an ICS or use of more than 9 canisters of SABA during the year and no more than $100 \mu \mathrm{g} / \mathrm{d}$ of ICS. Patel et al [20] considered extreme use as $>32$ puffs of salbutamol in any 24 -hour period. Belhassen et al [21] described SABA overuse as $\geq 12$ prescriptions/ dispensations over 12 months, while Lynd et al [22] defined excessive use as $>20$ canisters in a calendar year, a criterion that was adopted in the study recently published by Tavakoli et al [23]. We evaluated reliever medication used in the previous week based on GINA and US guidelines, which indicate that 
Table 3. Multivariate Analysis of Factors Related to Asthma Control

\begin{tabular}{|c|c|c|c|c|c|c|}
\hline & \multirow[t]{2}{*}{ B } & \multirow[t]{2}{*}{ ET } & \multirow[t]{2}{*}{ Sig } & \multirow[t]{2}{*}{$\operatorname{Exp}(B)$} & \multicolumn{2}{|c|}{$95 \% \mathrm{CI}$} \\
\hline & & & & & Low & High \\
\hline Age & -.021 & .008 & .013 & .980 & .964 & .996 \\
\hline $\begin{array}{l}\text { Asthma severity (reference: mild) } \\
\text { Moderate } \\
\text { Severe }\end{array}$ & $\begin{array}{l}-.910 \\
-.247\end{array}$ & $\begin{array}{l}.356 \\
.449\end{array}$ & $\begin{array}{l}.022 \\
.011 \\
.583\end{array}$ & $\begin{array}{l}.403 \\
.782\end{array}$ & $\begin{array}{l}.200 \\
.324\end{array}$ & $\begin{array}{l}.809 \\
1.884\end{array}$ \\
\hline Number of uses of reliever medication & -1.694 & .490 & .001 & .184 & .070 & .480 \\
\hline Salbutamol & -1.239 & .317 & .000 & .290 & .156 & .539 \\
\hline Beclomethasone-formoterol & -1.970 & .862 & .022 & .139 & .026 & .755 \\
\hline Terbutaline & -1.259 & .478 & .008 & .284 & .111 & .725 \\
\hline $\begin{array}{l}\text { Asthma self-perception } \\
\text { Partially controlled } \\
\text { Uncontrolled }\end{array}$ & $\begin{array}{c}-2.821 \\
-20.921\end{array}$ & $\begin{array}{c}.371 \\
5717.49\end{array}$ & $\begin{array}{l}.000 \\
.000 \\
.997\end{array}$ & $\begin{array}{l}.060 \\
.000\end{array}$ & $\begin{array}{l}.029 \\
.000\end{array}$ & $\begin{array}{c}.123 \\
-\end{array}$ \\
\hline
\end{tabular}

Table 4. Multivariate Analysis of Factors Related to Reliever Medication Use

\begin{tabular}{|c|c|c|c|c|c|c|}
\hline & \multirow[t]{2}{*}{$\mathrm{B}$} & \multirow[t]{2}{*}{ ET } & \multirow[t]{2}{*}{ Sig } & \multirow[t]{2}{*}{$\operatorname{Exp}(B)$} & \multicolumn{2}{|c|}{$95 \% \mathrm{CI}$} \\
\hline & & & & & Low & High \\
\hline Smoking habit (reference: nonsmoker) & & & 0.005 & & & \\
\hline Smoker & 1.426 & 0.482 & 0.003 & 4.160 & 1.618 & 10.699 \\
\hline Former smoker & 0.810 & 0.360 & 0.024 & 2.248 & 1.111 & 4.548 \\
\hline Number of night awakenings & 0.301 & 0.067 & 0.000 & 1.351 & 1.186 & 1.539 \\
\hline Asthma self-perception & & & 0.000 & & & \\
\hline Partially controlled & 1.084 & 0.404 & 0.007 & 2.955 & 1.338 & 6.528 \\
\hline Uncontrolled & 2.655 & 0.576 & 0.000 & 14.226 & 4.598 & 44.010 \\
\hline Asthma Control Questionnaire 5 & -1.330 & 0.482 & 0.006 & 0.264 & 0.103 & 0.680 \\
\hline
\end{tabular}

the use of reliever medication more than twice per week is suggestive of poor control [24]. This parameter is easily collected in clinical practice. According to this criterion, nearly a quarter of the sample used reliever medication inappropriately in our study. The criterion most similar to ours was that used by Fitzgerald et al [19], who evaluated inappropriate SABA use in 343520 patients (2 127592 patientyears of follow-up), but found that only $7.7 \%$ of patients used reliever medication inappropriately.

The outcomes associated with inappropriate use of SABAs have been extensively studied [25-27], and some reports provide factors that may be predictive of abusive use of SABAs. In 2013, Patel et al [28] published a study that related the use of salbutamol with the risk of future severe exacerbations, inadequate asthma control, and extreme overuse of salbutamol. In this study, the univariate analyses showed that the factors associated with an increased risk of subsequent SABA overuse were Maori ethnicity, a higher number of severe exacerbations in the preceding 12 months, a higher number of hospital admissions at any time, higher self-reported reliever use, lower $\mathrm{FEV}_{1}, \%$, and standard therapy. Fitzgerald et al [19] reported that inappropriate SABA use was related to both hospital admissions and emergency department visits. The recently published database study by Tavakoli et al [23] evaluated a cohort of 343520 individuals and identified the factors associated with increased likelihood of SABA overuse to be sex, age, having undergone a pulmonary function test, consulting a pulmonologist, consulting an allergist, visits to the physician, asthma-related hospitalization, appropriate use of ICSs, use of systemic corticosteroids, comorbidities, and the use of health resources. In all cases, the applicability of the results lies in identifying potential modifiable factors that can be taken into account when assessing the patient with asthma under treatment. The clinician can evaluate the presence or absence of these risk factors (eg, age and lower $\mathrm{FEV}_{1}, \%$ ) to decide whether to implement support measures or stricter monitoring. In our case, the perspective was slightly different, as we pointed out a factor that may alert the clinician to deterioration of the disease. Our hypothesis was that patients with factors indicating deteriorated clinical asthma would misuse reliever medication. As expected, there was a relationship between the misuse of reliever medication and the patient's asthma control and disease severity. The greater the severity, the greater the use of reliever medication. The GEMA and GINA guidelines also identified specific clinical parameters as markers of poor control or worsening of disease in their definition of an exacerbation as "an acute worsening of asthma symptoms leading to the need to increase the dose of ICS or to increase treatment by 
one step, use of oral or systemic corticosteroids, visits to the emergency department or other unscheduled health care visits, or need for hospitalization" [3]. In our study, misuse of reliever medications in the previous week was related to the following clinical variables: number of visits to the emergency department in the previous year, hospital admission in the previous year, increase in ICS therapy in the previous year, unscheduled visits in the previous year, and higher therapy step, which were more common in the HURM patients. Other clinical variables, such as the number of night awakenings in the previous 4 weeks, smoking habits, and sedentary lifestyle were more prevalent in patients who misused their reliever medication. Finally, our study showed no relationship between the number of times reliever medication was used and eosinophilia, although both parameters are markers of asthma severity (one a clinical variable and the other a laboratory variable) and are not associated with each other. We considered that this lack of relationship was likely due to different degrees of disease severity in the study population. Our results are very similar to those reported by Tavakoli et al [23], except that we did not compare factors such as sex or age, which did not differ between groups and comorbidities. However, our study evaluated current clinical measures and information reported directly from the patient (eg, control and adherence).

Our results on adherence are contradictory. We expected misuse of maintenance medication to be related to increased use of reliever medication; however, our results did not confirm this. In the study population, patients were predominantly adherent. The validation study of the TAI to Spanish [29], in which $62.5 \%$ of patients were nonadherent, revealed the same percentage, albeit grouping together good and intermediate adherence, and $76.2 \%$ of patients with poor adherence used reliever medication $\leq 2$ times per week. It is worth mentioning the significant relationship between the unwilling pattern and the misuse of reliever medication [28]. Patients may not be aware of their lack of adherence and its impact on asthma symptoms; this provides us with an opportunity to establish corrective measures in daily practice, such as patient education in the use and management of inhalers.

The main strength of this study was that it identified the potential of misusing reliever medication in the previous week - an extremely easy parameter to obtain - as an indicator of deterioration in terms of exacerbations, asthma control, and disease severity. Other limitations should be considered when interpreting the findings. The cross-sectional design of the study precludes establishing causal relationships and, therefore, performing further analysis of risk ratios. This must be taken into account when interpreting our results, as we cannot affirm whether misuse of reliever medication is the cause or the consequence of the absence of any of the related factors. Finally, the authors considered that the choice of the TAI could have affected the result obtained, because patient-reported outcomes are influenced by the patient's self-perception. Thus, it would be advisable to use electronic tools to demonstrate the relationship between misuse of reliever medication and adherence in future studies. Finally, it is pertinent to state that the intended sample size was not fully achieved, although this did not prevent us from finding differences between the groups. In the case of adherence, we were unable to rule out an influence.
In conclusion, our study highlights the importance of reliever medication in the previous week as a surrogate marker of poor asthma control, exacerbations, and disease severity. Unlike variables that require us to consult the clinical history for the previous year, patients can easily provide information on their use of reliever medication in the previous week. Therefore, this factor is easily incorporated into daily clinical practice. Nonetheless, the authors recognize that prospective follow-up studies are needed to discern the implications of this factor in the causal relationship between these factors and the use of reliever medication.

\section{Acknowledgments}

The authors are grateful for the editorial assistance of Antonio Torres-Ruiz (Dynamic Science S.L.). The opinions, interpretation of the data, and conclusions contained in this article are the responsibility of the authors. The authors would like to acknowledge the members of the MISTRAL Group of investigators: Xavier Flor, Centro de Atención Primaria Chafarinas; José Maria Vega, Hospital Regional Universitario de Málaga; Gustavo Luíz Mártinez, Hospital Vithas Xanit Internacional; Javier Pérez Fernández, Centro de Salud Calzada II; Xavier Muñoz, Hospital Vall D’Hebron; Albert Roger, Hospital Universitario German Trias i Pujol; Encarna Martínez Navarro, EAB Centelles; Elisa Gómez, Hospital de Ciudad Real; Ana Carmen Gil Adrados, Centro de Salud La Solana; Ruperto Gonzalez Pérez, AlergoCan; José Maria Hernández Pérez, Hospital General de la Palma; Francisco Javier González Barcala, Hospital Clínico Universitario de Santiago; Jaime Gonzálvez Rey, Centro de Salud Matama; Irina Diana Bobolea, Hospital 12 de Octubre; Silvia Sánchez García, Hospital Infantil Niño Jesús; José Tomás Gómez Sáenz, Centro de Salud de Nájera; Pilar Cebollera, Complejo Hospitalario de Navarra; Antolín López Viña, Hospital Universitario Puerta de Hierro; Eva Martínez Moragón, Hospital Dr. Peset; Antonio Valero, Hospital Clínic; Rocio Díaz Campos, Hospital 12 de Octubre; Ignacio García Talavera, Hospital Nuestra Señora de la Candelaria; Soledad Alonso Viteri, Hospital de Torrejón; José Carlos García Robaina, Hospital Nuestra Señora de la Candelaria; and Antonio Parra Arrondo, Hospital Abente y Lago.

\section{Funding}

This study received financial Support from AstraZeneca.

\section{Conflicts of Interest}

M Pérez and G Resler are employees of AstraZeneca Spain.

\section{References}

1. Global Initiative for Asthma (GINA). Available from: http:// www.ginasthma.org/documents/1/Pocket-Guide-for-AsthmaManagement-and-Prevention.

2. Guía Española Para el Manejo del Asma para Educadores 2007. Pag: 54.; Available from: www.gemasma.com.

3. Plaza Moral V. GEMA(4.0). Guidelines for Asthma Management. Arch Bronconeumol. 2015;51 Suppl 1:2-54. 
4. Demoly P, Annunziata K, Gubba E, Adamek L. Repeated crosssectional survey of patient-reported asthma control in Europe in the past 5 years. Eur Respir Rev. 2012;21(123):66-74.

5. Demoly P, Gueron B, Annunziata K, Adamek L, Walters RD. Update on asthma control in five European countries: results of a 2008 survey. Eur Respir Rev. 2010;19(116):150-7.

6. Partridge MR, van der Molen T, Myrseth SE, Busse WW. Attitudes and actions of asthma patients on regular maintenance therapy: the INSPIRE study. BMC Pulm Med. 2006;6:13.

7. Rabe KF, Vermeire PA, Soriano JB, Maier WC. Clinical management of asthma in 1999: the Asthma Insights and Reality in Europe (AIRE) study. Eur Respir J. 2000;16(5):802-7.

8. Olaguibel JM, Quirce S, Julia B, Fernandez C, Fortuna AM, Molina J, et al. Measurement of asthma control according to Global Initiative for Asthma guidelines: a comparison with the Asthma Control Questionnaire. Respir Res. 2012;13:50.

9. Haughney J, Price D, Kaplan A, Chrystyn H, Horne R, May N, et al. Achieving asthma control in practice: understanding the reasons for poor control. Respir Med. 2008;102(12):1681-93.

10. Doz M, Chouaid C, Com-Ruelle L, Calvo E, Brosa M, Robert J, et al. The association between asthma control, health care costs, and quality of life in France and Spain. BMC Pulm Med. 2013;13:15.

11. Pola-Bibian B, Dominguez-Ortega J, Vila-Nadal G, Entrala $A$, Gonzalez-Cavero L, Barranco $P$, et al. Asthma exacerbations in a tertiary hospital: clinical features, triggers, and risk factors for hospitalization. J Investig Allergol Clin Immunol. 2016:0.

12. Price $D$, Fletcher $M$, van der Molen T. Asthma control and management in 8,000 European patients: the REcognise Asthma and LInk to Symptoms and Experience (REALISE) survey. NPJ Prim Care Respir Med. 2014;24:14009.

13. Urrutia I, Plaza V, Pascual S, Cisneros C, Entrenas LM, Luengo MT, et al. Asthma control and concordance of opinions between patients and pulmonologists. J Asthma. 2013;50(8):877-83.

14. World Health Organization Asthma fact sheet.Date last updated: May 2011. Available from: www.who.int/mediacentre/ factsheets/fs307/en/index.html (accessed December 2015.

15. Suissa S, Ernst P, Boivin JF, Horwitz RI, Habbick B, Cockroft $D$, et al. A cohort analysis of excess mortality in asthma and the use of inhaled beta-agonists. Am J Respir Crit Care Med. 1994;149(3 Pt 1):604-10.

16. Sadatsafavi M, Lynd LD, Marra CA, FitzGerald JM. Dispensation of long-acting beta agonists with or without inhaled corticosteroids, and risk of asthma-related hospitalisation: a population-based study. Thorax. 2014;69(4):328-34.

17. Guía Española Para el Manejo del Asma para Educadores 2009. Available from: www.gemasma.com.

18. Plaza V, Fernandez-Rodriguez C, Melero C, Cosio BG, Entrenas $L M$, Perez de Llano $L$, et al. Validation of the 'Test of the Adherence to Inhalers' (TAI) for Asthma and COPD Patients. J Aerosol Med Pulm Drug Deliv. 2016;29(2):142-52.
19. FitzGerald JM, Tavakoli H, Lynd LD, Al Efraij K, Sadatsafavi M. The impact of inappropriate use of short acting beta agonists in asthma. Respir Med. 2017;131:135-40.

20. Patel M, Pilcher J, Reddel HK, Qi V, Mackey B, Tranquilino T, et al. Predictors of severe exacerbations, poor asthma control, and beta-agonist overuse for patients with asthma. J Allergy Clin Immunol Pract. 2014;2(6):751-8.

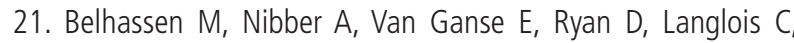
Appiagyei $F$, et al. Inappropriate asthma therapy-a tale of two countries: a parallel population-based cohort study. NPJ Prim Care Respir Med. 2016;26:16076.

22. Lynd LD, Guh DP, Pare PD, Anis AH. Patterns of inhaled asthma medication use: a 3-year longitudinal analysis of prescription claims data from British Columbia, Canada. Chest. 2002;122(6):1973-81.

23. Tavakoli H, Mark FitzGerald J, Lynd LD, Sadatsafavi M. Predictors of inappropriate and excessive use of reliever medications in asthma: a 16-year population-based study. BMC Pulm Med. 2018;18(1):33.

24. Bethesda (MD): National Heart L, and Blood Institute (US); Expert Panel Report 3: Guidelines for the Diagnosis and Management of Asthma. Clinical Practice Guidelines: 2007.

25. Camargo CA, Jr., Spooner CH, Rowe BH. Continuous versus intermittent beta-agonists in the treatment of acute asthma. Cochrane Database Syst Rev. 2003(4):CD001115.

26. Gerald JK, Carr TF, Wei CY, Holbrook JT, Gerald LB. Albuterol Overuse: A Marker of Psychological Distress? J Allergy Clin Immunol Pract. 2015;3(6):957-62.

27. Hong SH, Sanders BH, West D. Inappropriate use of inhaled short acting beta-agonists and its association with patient health status. Curr Med Res Opin. 2006;22(1):33-40.

28. Patel M, Pilcher J, Munro C, Hosking A, Pritchard A, Shaw D, et al. Short-acting beta-agonist use as a marker of current asthma control. J Allergy Clin Immunol Pract. 2013;1(4):3707.

29. Plaza V, Fernandez-Rodriguez C, Melero C, Cosio BG, Entrenas $L M$, de Llano LP, et al. Validation of the 'Test of the Adherence to Inhalers' (TAI) for Asthma and COPD Patients. J Aerosol Med Pulm Drug Deliv. 2016;29(2):142-52.

\section{Manuscript received October 10, 2018; accepted for publication February 7, 2019.}

\section{Urrutia}

Unit of Pulmonogy

Galdakao Hospital

OSI Barrualde-Galdakao, Biscay, Spain

E-mail: Isabelines.urrutialanda@osakidetza.eus 